\title{
The Molecular Mechanism of Protective Effects of Grape Seed Proanthocyanidin Extract on Reperfusion Arrhythmias in Rats in Vivo
}

\author{
Gaixia Zнао, ${ }^{a, b}$ Haiqing GAo, ${ }^{*, a, b}$ Jie QıU, ${ }^{a, b}$ Weida Lu, ${ }^{a, b}$ and Xinbing WeI ${ }^{c}$ \\ ${ }^{a}$ Department of Geriatrics, Shandong University Qilu Hospital; ${ }^{b}$ Shandong Provincial Key Laboratory of Cardiovascular \\ Proteomics, Qilu Hospital of Shandong University; Jinan 250012, China: and ${ }^{c}$ Institute of Pharmacology, Medicine \\ School, Shandong University; Jinan 250012, China. \\ Received November 3, 2009; accepted January 13, 2010; published online February 17, 2010
}

\begin{abstract}
Reperfusion arrhythmias (RA) especially ventricular tachycardia (VT) and ventricular fibrillation (VF) remain the most important causes of sudden death following reperfusion. In isolated rat hearts grape seed proanthocyanidin extract (GSPE) had been proved to reduce the incidence of reperfusion-induced VF and VT. However the mechanism of this protection remained unclear. The aim of this study was to elucidate the potential mechanism of this protection of GSPE. The myocardial ischemia reperfusion (IR) model was induced by 30 min coronary occlusion and $120 \mathrm{~min}$ reperfusion in open chest anesthetized rats. The ultrastructure of ischemic cardiomyocytes was observed. An isobaric tag labeling for relative and absolute quantification (iTRAQ) proteomics was used to identify differentially expressed membrane proteins. Western blot was performed to verify the results of iTRAQ. The results demonstrated GSPE can significantly reduce the incidence of VT and VF induced by reperfusion in vivo. We identified 92 differentially expressed proteins. Western blot analysis confirmed GSPE increased the expression of $\mathrm{Na}^{+} / \mathrm{K}^{+}$-ATPase $\alpha 1$ subunit $(p<0.01)$. We found the subunit distribution of $\mathrm{Na}^{+} / \mathrm{K}^{+}$ATPase was changed after reperfusion. $\mathrm{Na}^{+} / \mathrm{K}^{+}$-ATPase $\alpha 1$ subunit was decreased in IR group (without GSPEtreated) compared to sham group while it was significantly increased in GSPE group. The decrease of free radical generation induced by GSPE may lead to the up-regulation of $\mathrm{Na}^{+} / \mathrm{K}^{+}$-ATPase $\alpha 1$ subunit. This change of subunit distribution may lead to the increase of activity of $\mathrm{Na}^{+} / \mathrm{K}^{+}$-ATPase which may result in the protection of GSPE against reperfusion arrhythmias. Our experiments provided new avenues for the treatment of reperfusion arrhythmias.
\end{abstract}

Key words reperfusion arrhythmia; grape seed proanthocyanidin extract; oxygen free radical; $\mathrm{Na}^{+} / \mathrm{K}^{+}-\mathrm{ATPase} \alpha 1$ subunit; $\mathrm{Ca}^{2+}$ overload; isobaric tag labeling relative absolute quantification

Early reperfusion is crucial for the survival of ischemic myocardium. However, reperfusion has been referred by Braunwald and Kloner ${ }^{1)}$ as the "double edged sword" because reperfusion itself may lead to accelerated and additional myocardial injury beyond that generated by ischemia alone. This results in a spectrum of reperfusion-associated pathologies, collectively called "reperfusion injury."2) Reperfusion injury has been observed in each of reperfusion therapies including percutaneous coronary intervention (PCI), thrombolysis and coronary bypass grafting. The different clinical manifestations of this injury include myocardial necrosis, myocardial apoptosis, reperfusion arrhythmias, myocardial stunning and endothelial- and microvascular dysfunction including the no-reflow phenomenon. ${ }^{3)}$ However, ventricular tachycardia (VT) and ventricular fibrillation (VF) induced by reperfusion remain the most important causes of sudden death following spontaneous restoration of antegrade flow. ${ }^{4,5)}$ Therefore, every effort must be made to minimize sudden cardiac death caused by reperfusion arrhythmias. The mechanisms of reperfusion arrhythmias may include heterogeneous recovery of conduction and a refractory period of incomplete reperfusion, reentry, abnormal automaticities, and activities triggered by $\mathrm{Ca}^{2+}$ overload and free radicals. ${ }^{6-9)}$ However, the details of the mechanisms remain unclear and reperfusion arrhythmia has not received satisfactory treatment.

Grape seed proanthocyanidin extract (GSPE) is a natural, standardized, water-ethanol extract from red grape seeds which has great free radical scavenging ability. The main pharmacological effective components of GSPE are oligomeric proanthocyanidins. Free radicals and oxidative stress play a crucial role in the pathophysiology of a broad spectrum of cardiovascular diseases including congestive heart failure, valvular heart disease, cardiomyopathy, hypertrophy, atherosclerosis and ischemic heart disease. A series of studies were conducted using GSPE to demonstrate its cardioprotective ability in animals and humans. ${ }^{10-14)}$

Our previous work had shown GSPE reduced reperfusioninduced arrhythmias in rabbits. ${ }^{15)}$ In isolated rat hearts GSPE had been proved to reduce the incidence of reperfusion-induced VF and VT. ${ }^{11)}$ However the mechanism of this protection against reperfusion-induced VT, VF by GSPE remained unclear. Proteomic studies of heart tissues can provide new insights into the specific early molecular mechanisms that underlie the responses to ischemia reperfusion (IR) injury and therefore may have vital implications for the specificity and efficacy of diagnosis and treatment. Despite their biological significance, the investigation of membrane proteomics is technically limited by the relatively high molecular masses and hydrophobicities of these proteins. ${ }^{16)}$ With the development of proteomic techniques a quantitative proteomics-isobaric tags for relative and absolute quantification (iTRAQ) was introduced to solve these problems. iTRAQ employs primary amine reactive isobaric tags to derivatize peptides at the N-termini and lysine side-chains. Therefore, theoretically, iTRAQ labels most of the peptide fragments in a digested mixture. Although the peptides labeled with any of the iTRAQ reagents are indistinguishable in single MS analysis, 
tag fragmentation during MS/MS analysis produces reporter ions $(m / z=114,115,116,117)$, which provide quantitative information upon integration of the peak areas. ${ }^{17)}$

In the present study, to elucidate the molecular mechanism of the protective effect of GSPE against VT, VF induced by reperfusion, IR modals were made in vivo. Hearts (in IR and GSPE group) were subjected to $30 \mathrm{~min}$ of ischemia induced by the occlusion of left anterior descending coronary artery (LAD) which was followed by $2 \mathrm{~h}$ of reperfusion. The iTRAQ proteomics was used to generate a list of differentially expressed membrane proteins that are putatively involved in the protective effects of GSPE on reducing the incidence of reperfusion-induced VT, VF. We identified 92 proteins that were differentially expressed between GSPE treated rats and non-GSPE treated rats. We discussed the possible functions of the identified proteins in the protective effects.

\section{MATERIALS AND METHODS}

Animal Protocol Male Wistar rats (body weight: 180$200 \mathrm{~g}$ ) were purchased from Laboratory Animal Center of Shandong University (Shandong, China). Animals were housed in wire-bottomed cages ( 2 rats in each) for $5 \mathrm{~d}$ before the study began. All procedures were approved by the animal ethics committee of Shandong University. Throughout the study, the rats were maintained on a 12-h dark-light cycle in a temperature-controlled $\left(21 \pm 2{ }^{\circ} \mathrm{C}\right)$ room with free access to standard laboratory non-purified diet and tap water. Thirty six rats were randomly assigned to three groups: Sham group $(n=12)$, IR group $(n=12)$ and GSPE group $(n=12)$. Twelve rats in GSPE group were fed with GSPE $(200 \mathrm{mg} / \mathrm{kg} / \mathrm{d}$ for 4 weeks, intragastricly) while the other 24 rats were given $0.9 \% \mathrm{NaCl}$ intragastricly only for 4 weeks.

Grape Seed Proanthocyanidin Extract (GSPE) We used a commercially available grape seed proanthocyanidin extract which were purchased from Jianfeng, Inc. (Tianjin, China). Gas chromatography-mass spectrometry analyses in conjunction with HPLC showed that this GSPE contains 56\% dimeric proanthocyanidins, $12 \%$ trimeric proanthocyanidins, $6.6 \%$ tetrameric proanthocyanidins, and small amounts of monomeric and high-molecular-weight oligomeric proanthocyanidins and flavonoids; lot No. GO50412. GSPE were diluted with $0.9 \% \mathrm{NaCl}$.

Experimental Procedure. Ischemia Reperfusion (IR) IR Protocol in Rats in Vivo: Rats $(280-340 \mathrm{~g})$ were anaesthetized with $20 \%$ Urethane $(0.5 \mathrm{ml} / 100 \mathrm{~g}$, intraperitoneally). Body temperature was routinely monitored via a rectal thermometer using a heated operating platform and appropriate heating lamps. Subdermal electrodes were placed to allow the determination of a lead II electrocardiogram (ECG) which was recorded continuously throughout the experiment by the BL410 multichannel acquisition system (Chengdu Taimeng, China) for physiological signals. The incidence of reperfusion-induced VF and VT during reperfusion was analyzed. The trachea was cannulated for artificial respiration. The chest was opened by a left thoracotomy, followed by sectioning of the 4 th and 5 th ribs, approximately $2 \mathrm{~mm}$ to the left of the sternum. Artificial respiration was started immediately with room air (volume $2 \mathrm{ml} / 100 \mathrm{~g}$, rate 54 strokes/min). After incision of the pericardium, the heart was exteriorized using gentle pressure on the rib cage. A 4-0 polypropylene suture through a 3-mm long polyethylene tube (PE-10) was then placed around the left anterior descending coronary artery (LAD), proximal to its main branching point. The heart was replaced in the chest, and the rat was allowed to recover for $15 \mathrm{~min}$. At this point, any animals exhibiting significant ventricular arrhythmias were discarded from the study. ${ }^{18)}$ Then the LAD was ligated with the $4-0$ suture. The coronary artery was occluded by tightening of the occluder. This was associated with the typical electrocardiographic (ST-segment elevation and increase in R-wave amplitude). After $30 \mathrm{~min}$ of ischemia, in the IR and GSPE groups, the suture around the LAD was removed and the occurrence of reperfusion was assessed by the observation of blood flow in the epicardial coronary arteries through a surgical microscope. The ischemic myocardium was reperfused for $120 \mathrm{~min}$. Sham group were made following an identical procedure but without the actual tying of the polypropylene suture.

Immediately when the reperfusion was over the heart was excised and cleared of blood by rinsing in isotonic saline $\left(0^{\circ} \mathrm{C}\right)$. In the IR and GSPE group, the ischemic area was cut out whilst in the sham-operated animals the corresponding left ventricular region was taken. Only these tissue samples were snap frozen in liquid nitrogen, stored at $-80^{\circ} \mathrm{C}$ and used whole for further study.

Assessments of VT and VF: A heart was considered to be in VF if an irregular undulating baseline was apparent on the electrocardiogram. VT was defined as $\geq 5$ consecutive premature ventricular complexes. This classification included repetitive monomorphic VT, which is difficult to dissociate from rapid VT. The heart was considered to be in sinus rhythm if normal sinus complexes occurring in a regular rhythm were apparent on the screen. ${ }^{19)}$

iTRAQ Proteomics Preparation of the Membrane-Enriched Fraction: Same amount of heart tissues from six rat models were mixed and cut into small slices. Suspend the tissue slices in hypotonic buffer (10 mm $N$-(2-hydroxyethyl)piperazine- $N^{\prime}$-2-ethanesulfonic acid, $\mathrm{pH} 7.5,1.5 \mathrm{~mm} \mathrm{MgCl}_{2}$, $10 \mathrm{~mm} \mathrm{KCl}, 1 \mathrm{~mm}$ phenylmethylsulfonyl fluoride (PMSF)) and homogenized with a Dounce homogenizer. The membrane fraction was purified by three-step centrifugation. First nuclei were pelleted by centrifugation at $3000 \boldsymbol{g}$ for $30 \mathrm{~min}$ at $4{ }^{\circ} \mathrm{C}$. The post nuclear supernatant was then centrifuged at $8000 \mathrm{~g}$ for $30 \mathrm{~min}$ at $4^{\circ} \mathrm{C}$ to remove mitochondria. The membrane fraction was lastly obtained by centrifugation of the post mitochondria supernatant at $150000 \boldsymbol{g}$ for $30 \mathrm{~min}$ at $4{ }^{\circ} \mathrm{C}$, followed by 3 times wash with $0.1 \mathrm{M} \mathrm{Na}_{2} \mathrm{CO}_{3}(\mathrm{pH} 11.5)$. The membrane pellet was dissolved in lysis buffer containing $6 \mathrm{~m}$ urea, $5 \mathrm{~mm}$ ethylenediaminetetraacetic acid, 2\% sodium dodecyl sulfate (SDS) and $1 \mathrm{~mm}$ PMSF.

Digestion of the Membrane-Enriched Fraction: After quantification with $\mathrm{BCA}$ kit, $100 \mu \mathrm{g}$ of proteins for each sample were treated with $10 \mathrm{~mm}$ dithiothreitol (DTT) at $60^{\circ} \mathrm{C}$ for $1 \mathrm{~h}$ and $55 \mathrm{~mm}$ iodoacetamide at room temperature in dark for $45 \mathrm{~min}$, respectively. Gel-assisted digestion was then performed. Briefly, the membrane proteins were incorporated into the gel by adding $18 \mu \mathrm{l}$ of acrylamide/bisacrylamide $(30 \%, \mathrm{v} / \mathrm{v}, 29: 1), 2.5 \mu \mathrm{l}$ of $10 \%(\mathrm{w} / \mathrm{v})$ ammonium persulfate and $1 \mu \mathrm{l} N, N, N^{\prime}, N^{\prime}$-tetramethylethylenediamine into the protein solution. The gel was cut into small pieces and washed 3 times with dissociation buffer containing 50\% acrylonitrile 
(ACN). The gel samples were further dehydrated with $100 \%$ ACN and completely dried. Finally, tryptic digestion was performed in dissociation buffer at $37^{\circ} \mathrm{C}$ overnight (trypsin : protein $=1: 30$ ).

Labeling the Peptides With iTRAQ Reagents: The peptides were labeled with iTRAQ reagents (114 for the peptides of Sham group, 116 for the peptides of GSPE group, and 118 for the peptides of IR group respectively).

Fifty microliters of isopropanol was added into each iTRAQ reagent vial and then transferred to the sample tube. After incubated at room temperature for $2 \mathrm{~h}$, the contents of all iTRAQ reagent-labeled sample tubes were combined into one tube.

Strong Cation Exchange (SCX) and C18 Column Fractionation: The sample was diluted with 10 folds of Cation Exchange Buffer A (10 mm $\mathrm{KH}_{2} \mathrm{PO}_{4}$ in $25 \%$ acetonitrile at $\mathrm{pH} 2.5-3.0$ ). High-resolution cation exchange chromatography was then performed to separate the labeled samples into 10 fractions. The gradient was buffer $\mathrm{B}\left(10 \mathrm{mM} \mathrm{KH}_{2} \mathrm{PO}_{4}, 2 \mathrm{M}\right.$ $\mathrm{KCl}$ in $25 \%$ acetonitrile at $\mathrm{pH} 2.5-3.0) 0-30 \%, 30 \mathrm{~min}$. Samples were desalted and further fractionated by using $\mathrm{C} 18$ column on nano HPLC (PROXEOME, America) followed by $\mathrm{MS}$ analysis. The gradient was set as 5-40\% $\mathrm{ACN}$ in $70 \mathrm{~min}$.

Matrix Assisted Laser Desorption Ionization-Time of Flight (MALDI-TOF)/TOF and MicroQ-TOF Analysis: The spectra were acquired in reflection mode in MALDITOF/TOF with mass range 700 -4000 and the machine parameters set as, ion source $25 \mathrm{kV}$ for positive matrix factorization (PMF) and $8.0 \mathrm{kV}$ for tandem MS/MS, lens $9.5 \mathrm{kV}$ for $\mathrm{PMF}$ and $3.5 \mathrm{kV}$ for tandem $\mathrm{MS} / \mathrm{MS}$, reflector $26.3 \mathrm{kV}$ for PMF and $29.5 \mathrm{kV}$ for tandem MS/MS, lift $19.0 \mathrm{kV}$. The peaks with ratio of $\mathrm{S} / \mathrm{N}$ over 5 were automatically labeled by FlexAnalysis (Bruker, Germany). The PMF peaks with mass intensity more than 5000 were selected for further MS/MS.

The spectra were acquired in positive ion mode in microQTOF with mass range $50-3000$, the dry gas and the nebulizer gas was set as $31 / \mathrm{min}$, and $21 / \mathrm{min}$, respectively. The temperature of the spray chamber was set as $150^{\circ} \mathrm{C}$, and the strength electric field was set as $-1400 \mathrm{~V}$, the collision energy was set as 35\% timing for low ion mass and 65\% timing for high ion mass. Other parameters were set as default.

Database Search: The spectra were processed with microQ-TOF control 3.0 (Bruker, Germany) using default settings, except the parameters of transfer funnel RF and collision cell RF were set as $120 \mathrm{Vpp}$ and $600 \mathrm{Vpp}$, respectively. The subsequent data analysis was carried out using the Data Analysis 4.0 Biotools 3.0 (Bruker, Germany), WARP-LC 2.0 (Bruker, Germany), and Mascot 2.2 (Matrix Science, London, U.K.), respectively. Protein identification was performed by searching the SWISSPROT Rattus database with a precursor ion and fragment mass tolerance both set as $0.04 \mathrm{Da}$. Carbamidomethylation of cysteines was set as fixed modification, and oxidation of methionines, iTRAQ 8 plex modification of $\mathrm{N}$ terminal, $\mathrm{K}$ and $\mathrm{Y}$ were considered as variable modifications, respectively. One maximum miscleavage was accepted. The ion score cutoffs were set to 25 for peptides and to 68 for proteins. Peptide identifications were accepted if they could be established at greater than $90.0 \%$ probability as specified by the peptide prophet algorithm. Protein identifications were accepted if they could be established at greater than $90.0 \%$ probability or contained at least 2 identified peptides. Proteins that contained similar peptides and could not be differentiated based on MS/MS analysis alone were grouped to satisfy the principles of parsimony. For classification, the gene ontology (GO) symbols of the identified proteins were curated using the XRef database, and queried against the gene ontology database using the GoMiner tool (http://discover.nci.nih.gov/gominer/index.jsp). Prediction of the origin of proteins with unknown cellular localization was performed using the PSORTII (http://www.psort.org/).

Western Blot Membrane proteins $(20 \mu 1)$ were separated by electrophoresis in a SDS-polyacrylamide gel. After the proteins were transferred onto a polyvinylidene difluoride membrane (Millipore, Bedford, MA, U.S.A.), the blot was incubated with blocking buffer $(1 \times$ PBS and 5\% non-fat dry milk) for $1 \mathrm{~h}$ at room temperature and then probed with anti$\mathrm{Na}^{+} / \mathrm{K}^{+}$-ATPase $\alpha 1 \quad(1: 200$, Santa Cruz, U.S.A. $)$ monoclonal antibody, followed by incubation with secondary antibody, horseradish peroxidase conjugated affinity goat antimouse immunoglobulin $\mathrm{G}(\mathrm{IgG})(1: 3000)$ for $1 \mathrm{~h}$. To control equal loading of total protein in all lanes, blots were stained with mouse anti $\beta$-actin antibody. The intensities were quantified with a densitometric analysis (Digital Protein DNA Imagineware, Huntington Station, NY, U.S.A.).

Ultrastructure Observation Ultrathin sections cut from the ischemic area were stained with uranylacetate and lead citrate and were examined with an H-800 electron microscope (Hitachi, Japan).

Statistical Analysis Statistic analysis was performed with SPSS 11.5 software. The ECG data were retrospectively analyzed in a blind manner for the incidence of reperfusioninduced VT, VF. Chi-square test was used to analyze the ECG data. Protein expression ratios were shown as means \pm S.D. Newman-Keuls test was used to evaluate data, considering $p<0.05$ to indicate a statistically significant difference.

\section{RESULTS}

Reduction of the Incidence of Reperfusion-Induced VT, VF by GSPE Our results demonstrated that GSPE can significantly reduce the incidence of reperfusion-induced VT, VF. There was no arrhythmia happened in Sham group. The incidence of reperfusion-induced VF was reduced from $64 \%$ in rats without GSPE-treated (IR group) to $17 \%$ in rats treated with GSPE (GSPE group) $(p<0.05)$. The incidence of reperfusion-induced VT was reduced from $91 \%$ in rats without GSPE-treated to $33 \%$ in rats with GSPE-treated $(p<0.01)$ (as shown in Fig. 1).

Results of Transmission Electron Microscopic Observation As shown in Fig. 2, specimens from sham group showed normal features: the cardiac cells were rich in mitochondria arranged between myofibrils in rows with myofibrils arranged evenly and normal intercalated disks. The sarcomere was of the same length. Nuclear membrane was integrated and chromatin was normally distributed. In IR group, the structure abnormalities of nuclear were apparently observed. Disarrangement, breakage and local absence of myofibrils were observed. Numerous disarranged mitochondria substituted for myofibrils. Mitochondria vacuolization and crista loss were observed. In GSPE group there were more apparent differences. The protective effect was acquired in 
Incidence of Reperfusion Arrhythmias

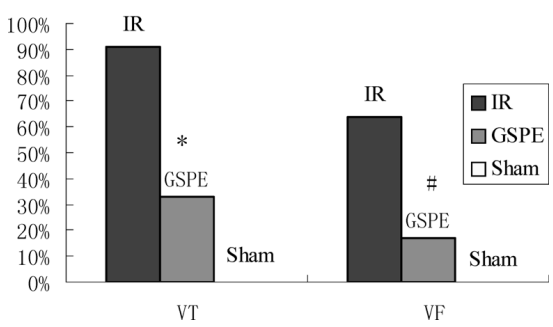

Fig. 1. Shows the Reduction of the Incidence of Reperfusion-Induced VT, VF by GSPE in Sham, GSPE and IR Groups

$* p<0.01$ GSPE $v s$. IR, $\# p<0.05$ GSPE $v s$. IR. VT: ventricular tachycardia, VF: ven tricular fibrillation.

that there were only moderate mitochondrial and nucleolus abnormalities in cardiac myocytes.

Identification of Membrane Proteins The membraneenriched fractions were digested by tripsin. The resulting complex peptide mixtures were labeled with iTRAQ reagents (114 for the peptides of Sham group, 116 for the peptides of GSPE group, and 118 for the peptides of IR group, respectively), and then separated by SCX and C18 fractionation. And 6 SCX fractions were analyzed by MALDI-TOF/TOF and microQ-TOF. Although the peaks derived from three of the isotopic tags were indistinguishable in the single MS analysis, upon tag fragmentation in $\mathrm{MS} / \mathrm{MS}$, peaks derived from the reporter tags $(m / z=114,116,118)$ were distinguished and the fragmentation along the peptide backbone results in b- and y-type fragments, which may be used to identify the peptide sequence. The relative quantities of peptides prepared from the three different sources were analyzed based on the integration of peak areas.

We identified 92 differential proteins among which the expression of 9 proteins was significantly changed. The expression of 3 proteins were down-regulated by GSPE including annexin 6, carnitine $O$-palmitoyltransferase 1 , leucine zipperEF-hand-containing transmembrane protein 1 and the expression of 6 proteins were up-regulated by GSPE including $\mathrm{Na}^{+} / \mathrm{K}^{+}$-ATPase $\alpha 1$, platelet glycoprotein 4 , voltage-dependent anion-selective channel protein 1 (VDAC-1), prohibitin, aspartate aminotransferase, $60 \mathrm{kDa}$ heat shock protein. Table 1 showed the name, access number in Swiss-prot, protein expression ratio, molecular weight, and functions of 3 proteins down-regulated by GSPE. Table 2 showed the name, access number in Swiss-prot, protein expression ratio, molecular weight, and functions of 6 proteins up-regulated by GSPE. Figure 3 showed representative MS/MS spectra for peptides derived from $\mathrm{Na}^{+} / \mathrm{K}^{+}$-ATPase $\alpha 1$.

Western Blot Analysis To confirm the results of iTRAQ, we carried out Western blot analysis of $\mathrm{Na}^{+} / \mathrm{K}^{+}$ATPase $\alpha 1$. GSPE increased the expression of $\mathrm{Na}^{+} / \mathrm{K}^{+}$. ATPase $\alpha 1 \quad(p<0.01)$ which meet the result of iTRAQ as shown in Fig. 4.

\section{DISCUSSION}

In 1977, Bulkely and Hutchins ${ }^{20)}$ reported the paradox of myocardial necrosis after successful revascularization by coronary artery bypass graft surgery and suggested the lesions were surgery related and represented contracture due to

\section{A Sham group}

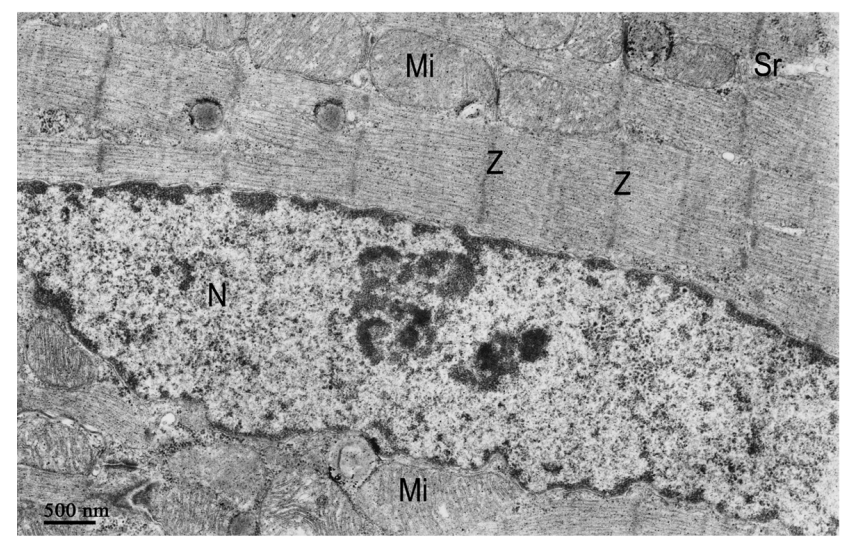

\section{B IR group}

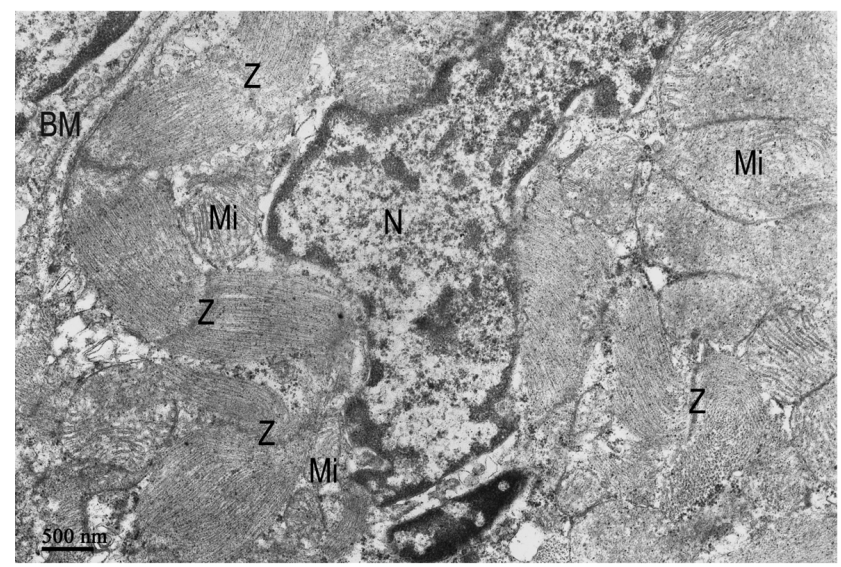

\section{GSPE group}

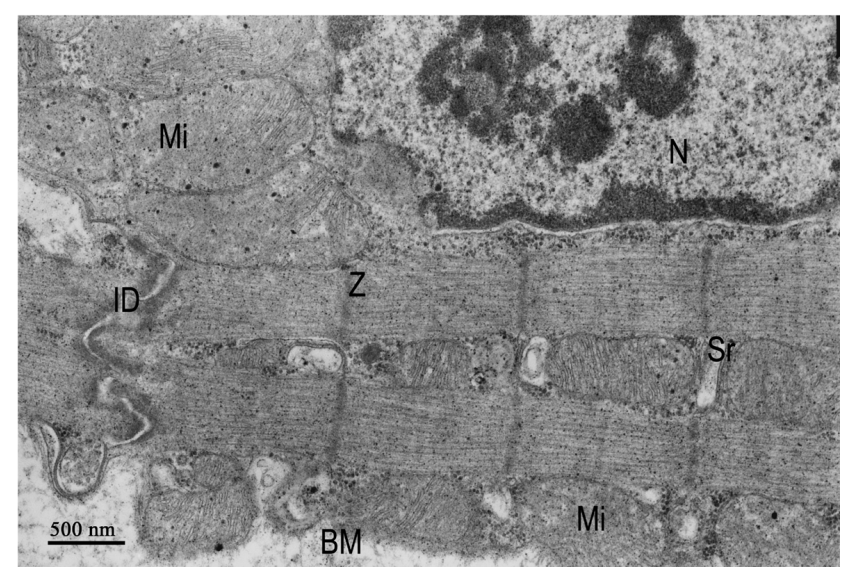

Fig. 2. Shows Electron Microscopic Examinations of Rat Myocardium Nucleus, Sarcomere and Mitochondria in Sham, GSPE and IR Groups (AC)

(A) Sham group, (B) IR group, (C) GSPE group. In Fig. 2, $\mathrm{N}$ means nuclear. $\mathrm{Sr}$ means sarcoplasma reticulum. Mi means mitochondria. ID means intercalated disks. Z means sarcomere. BM means basement membrane.

calcium loading and myocardial cellular edema in the distribution of widely patent grafts. The recognition that thrombotic occlusion of a coronary artery results in a wave front of irreversible myocardial cell injury extending from the subendocardium to the subepicardium in a time-dependent fashion, led to the introduction of reperfusion therapy for acute my- 
Table 1. Proteins Identified as GSPE Down-Regulated through iTRAQ MS/MS (Showed the Name, Access Number in Swiss-Prot, Protein Expression Ratio, Molecular Weight, and Functions of Proteins Down-Regulated by GSPE)

\begin{tabular}{|c|c|c|c|c|c|}
\hline Protein name & $\begin{array}{l}\text { Access } \\
\text { number in } \\
\text { Swiss-prot }\end{array}$ & Function & $\begin{array}{l}\text { Molecular } \\
\text { weight } \\
\text { [kDa] }\end{array}$ & $\begin{array}{c}\text { Protein expression } \\
\text { ratio } \\
(118 / 114)^{a)}\end{array}$ & $\begin{array}{c}\text { Protein expression } \\
\text { ratio } \\
(116 / 114)^{b)}\end{array}$ \\
\hline Annexin 6 & P48037 & Calcium ion binding & 76.10563 & 1.8 & 1.63 \\
\hline Carnitine $O$-palmitoyltransferase 1 & Q63704 & Fatty acid metabolism & 89.12859 & 1.57 & 1 \\
\hline $\begin{array}{l}\text { Leucine zipper-EF-hand-containing } \\
\text { transmembrane protein } 1\end{array}$ & O95202 & Calcium ion binding & 83.98621 & 1.43 & 0.85 \\
\hline
\end{tabular}

a) Means IR group versus sham group; b) means GSPE group versus sham group. 114 means sham group; 116 means GSPE group; 118 means IR group.

Table 2. Proteins Identified as GSPE Up-Regulated through iTRAQ MS/MS (Showed the Name, Access Number in Swiss-Prot, Protein Expression Ratio, Molecular Weight, and Functions of Proteins Up-Regulated by GSPE)

\begin{tabular}{|c|c|c|c|c|c|}
\hline Protein name & $\begin{array}{c}\text { Access } \\
\text { number in } \\
\text { Swiss-prot }\end{array}$ & Function & $\begin{array}{l}\text { Molecular } \\
\text { weight } \\
{[\mathrm{kDa}]}\end{array}$ & $\begin{array}{c}\text { Protein expression } \\
\text { ratio } \\
(118 / 114)^{a)}\end{array}$ & $\begin{array}{c}\text { Protein expression } \\
\text { ratio } \\
(116 / 114)^{b)}\end{array}$ \\
\hline $\mathrm{Na}^{+} / \mathrm{K}^{+}$-ATPase $\alpha 1$ & Q8VDN2 & Ion transport & 114.2213 & 0.82 & 1.37 \\
\hline Platelet glycoprotein 4 & Q07969 & $\begin{array}{l}\text { Cell adhesion, fatty acid } \\
\text { oxidation }\end{array}$ & 53.26751 & 0.64 & 0.98 \\
\hline $\begin{array}{l}\text { Voltage-dependent anion-selective } \\
\text { channel protein } 1 \text { (VDAC-1) }\end{array}$ & Q9Z2L0 & Anion transport, apoptosis & 30.85061 & 0.77 & 1.07 \\
\hline Prohibitin & P35232 & $\begin{array}{l}\text { Regulation of apoptosis, } \\
\text { signal transduction }\end{array}$ & 29.84292 & 0.79 & 1.1 \\
\hline Aspartate aminotransferase & P00507 & Fatty acid transport & 47.68325 & 0.42 & 0.9 \\
\hline $60 \mathrm{kDa}$ heat shock protein & Q5NVM5 & Chaperone, apoptosis & 61.1304 & 0.61 & 1.59 \\
\hline
\end{tabular}

a) Means IR group versus sham group; b) means GSPE group versus sham group. 114 means sham group; 116 means GSPE group; 118 means IR group.

ocardial infarction. ${ }^{21,22)}$ Reperfusion injury has been observed in the reperfusion therapies including thrombolysis, PCI and coronary bypass grafting. In the clinical setting, reperfusion injury after revascularization of the ischemiarelated artery is manifested by myocardial stunning, reperfusion arrhythmia, myocyte death, and endothelial- and microvascular dysfunction including the no-reflow phenomenon. ${ }^{3)}$ The clinical importance of reperfusion-induced arrhythmias is based on evidence of their role in sudden cardiac death. VT and VF induced by reperfusion remain the most important causes of sudden death following spontaneous restoration of antegrade flow. ${ }^{4,5)}$ The reasons for unsuccessful prevention of sudden death may be, in part, that reperfusion arrhythmias are unresponsive to antiarrhythmic drugs with purported benefit in ischemia. ${ }^{4)}$ The pathophysiological mechanism responsible for their initiation and maintenance are multifactorial. It has been suggested that the overproduction of oxygen-derived free radicals and calcium overload during the first minutes of reflow might be involved. However, oxygen-derived free radicals and hypercontracture due to calcium-overload are not the only candidates responsible for reperfusion injury. Other factors of importance in the pathogenesis of reperfusion injury include platelet- and neutrophil-mediated injury, the renin-angiotensin system and the complement activation. ${ }^{3)}$ However, till today the underlying pathophysiological mechanisms of IR have not been fully elucidated. What's more, the therapy for reperfusion-induced arrhythmias isn't satisfactory. Most antiarrhythmic drugs available, however, have limitations arising from their toxic and proarrhythmic potential. That a variety of antiarrhythmic drugs have been associated with an increased mortality has been a disturbing observation. ${ }^{23)}$ Thus, research and development of new agents and treatment modalities for reperfusion arrhythmias are severely needed.

GSPE has been reported to have protective effects against cardiac disorders. ${ }^{12,13,24)}$ It has also been suggested to have protective effects against myocardial reperfusion injury which maybe mediated through its antioxidative and antiapoptosis effect. ${ }^{10)}$ In the in vitro model, GSPE exhibited concentration-dependent dramatic scavenging ability towards biochemically generated superoxide anion, hydroxyl and peroxyl radicals, and provided significantly better scavenging as compared to Vitamins $\mathrm{C}$ and E. ${ }^{11,25)}$ In addition to the ability to scavenge oxygen free radicals, GSPE has the ability to stimulate other cardioprotective pathways. Study had shown that GSPE stimulated nitric oxide production in untreated cardiomyocytes in a dose-dependent manner. ${ }^{14)}$ However the molecular mechanisms of the cardioprotection of GSPE are not fully elucidated.

Membranes are crucial for the life of a eukaryotic cell. Despite their various cellular functions, all membranes have a common general structure: a thin highly dynamic bilayer of lipids and proteins embedded within the lipid bilayer mainly by non-covalent interactions. Approximately $20-30 \%$ of the genes in vertebrates encode integral membrane proteins. ${ }^{26)}$ These membrane proteins and associated peripheral membrane proteins are involved in central cellular processes and account for the major pharmaceutical drug targets. ${ }^{27)}$ That's why we focused on the differentially expressed membrane proteins. Proteomic studies of heart tissues could generate a list of differential proteins which may provide new insights into the specific early molecular mechanisms that underlie the responses to IR injury and therefore may have important implications for the diagnosis and treatment. Despite their biological significance, the investigation of membrane proteomics is technically limited by the relatively high molecu- 
A
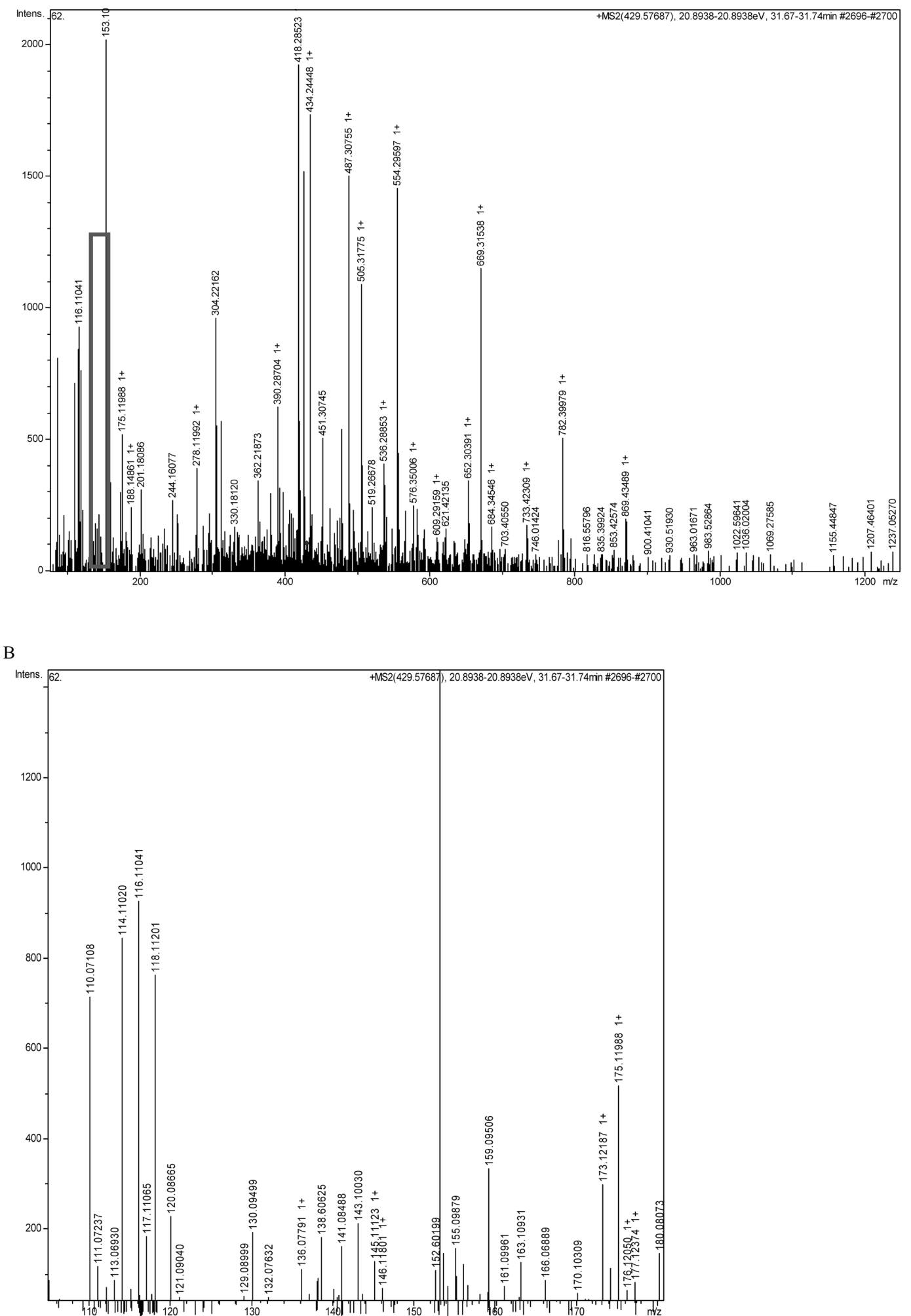

Fig. 3. Shows Representative MS/MS Spectra for Peptides Derived from $\mathrm{Na}^{+} / \mathrm{K}^{+}$-ATPase $\alpha 1$ (A, B)

(A) MS/MS spectra for peptide 429 derived from $\mathrm{Na}^{+} / \mathrm{K}^{+}$-ATPase $\alpha 1$. (B) The peak areas for each of the iTRAQ signature ions $(114.1,116.1,118.1)$ enable quantification of the peptides and proteins.

lar masses and hydrophobicities of these proteins. ${ }^{16)}$ In addition, there are difficulties with the separation of very highly glycosylated and/or phosphorylated membrane proteins, especially in electrophoretic and chromatographic analyses such as 2-DE and RP LC. With the development of pro- teomic techniques, in this study a new quantitative proteomics-iTRAQ proteomics was introduced to solve these problems.

After digesting the membrane-enriched fractions with tripsin, the resulting complex peptide mixtures were labeled 
Effects of GSPE on the expression of $\mathrm{Na}^{+} / \mathrm{K}^{+-}$ ATPase a 1

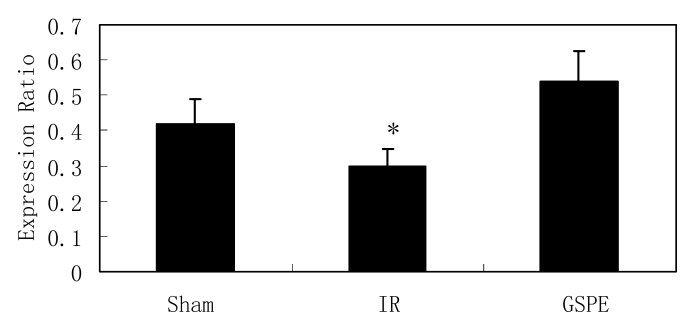

Fig. 4. Showed the Relative Amounts of $\mathrm{Na}^{+} / \mathrm{K}^{+}$-ATPase $\alpha 1$ by Western Blot Analysis

Data were expressed as the expression ratio of $\mathrm{Na}^{+} / \mathrm{K}^{+}$-ATPase $\alpha 1 / \beta$-actin and given as mean \pm S.D. from three groups: Sham, IR, and GSPE. $* p<0.01$, IR $v s$. GSPE.

with iTRAQ reagents (114 for the peptides of Sham group, 116 for the peptides of GSPE group, and 118 for the peptides of IR group respectively), and then separated by SCX and C18 fractionation. This means of digestion and separation is a good way to solve the problems of separating very highly glycosylated and/or phosphorylated membrane proteins. And the $6 \mathrm{SCX}$ fractions were analyzed by MALDI-TOF/TOF and microQ-TOF. Because iTRAQ employs primary amine reactive isobaric tags to derivatize peptides at the $\mathrm{N}$-termini and lysine side-chains, theoretically, iTRAQ could label most of the peptide fragments in a digested mixture. Because of the isobaric nature of these reagents, the same peptide from each sample appears as a single peak in the MS spectrum, thus reducing the complexity in the MS spectrum when compared with an isotopic labelling technique such as ICAT (isotope coded affinity tag). ${ }^{28)}$ Upon collision-induced dissociation, the iTRAQ-tagged peptides fragment to release reporter ions (at 114,116, $118 \mathrm{~m} / \mathrm{z}$ ) and $\mathrm{b}$ - and $\mathrm{y}$-ion series among other fragments. The peak area of the reporter ions are used to assess relative abundance of peptides and consequently the proteins from which they are derived and the $b$ - and y-ion series may be used to identify the peptide sequence. ${ }^{17)}$

To date, we firstly applied iTRAQ combined with mass spectrometry to identify alterations in the expression of membrane protein in myocardial tissue in order to elucidate the potential molecular mechanism of the protective effects of GSPE on reperfusion-induced VT, VF and find potential new drug targets for reperfusion arrhythmias. Studies showed GSPE caused a striking reduction in the incidence of reperfusion-induced VF and VT in rat hearts in vitro ${ }^{19)}$ and our previous work confirmed the protection of GSPE against reperfusion-induced VT, VF in rabbits in vivo. ${ }^{15)}$ In this study the ultrastructure observation showed that the rats treated with GSPE were much less vulnerable to IR injury than the rats without GSPE-treated. The analysis of ECG indicated that GSPE significantly reduced the incidence of reperfusioninduced VT, VF in rats in vivo.

We identified 92 differential proteins among which the expression of 9 proteins was significantly changed. The expression of 3 proteins were down-regulated by GSPE including annexin 6, carnitine $O$-palmitoyltransferase 1 , leucine zipperEF-hand-containing transmembrane protein 1 and the expression of 6 proteins were up-regulated by GSPE including $\mathrm{Na}^{+} / \mathrm{K}^{+}$-ATPase $\alpha 1$, platelet glycoprotein 4 , voltage-dependent anion-selective channel protein 1 (VDAC-1), prohibitin, aspartate aminotransferase, $60 \mathrm{kDa}$ heat shock protein. The functions of these differentially expressed proteins included anion transport, fatty acid oxidation, calcium ion binding, cell adhesion, regulation of apoptosis, signal transduction which indicate that these processes may take part in the protective effects of GSPE against reperfusion-induced injury.

Annexin 6 was down-regulated in GSPE group compared to IR group. This protein may be involved directly or indirectly in the protection of GSPE against reperfusion injury. The annexin family binds $\mathrm{Ca}^{2+}$ and anionic phospholipid membrane surfaces where they self-associate into trimeric units to form larger "sheet" complexes. The annexin "trimers," in turn, form a two-dimensional lattice structure which extends across phospholipid membranes and alter the underlying membrane permeability by sequestering specific phospholipids. ${ }^{29,30)}$ Immunological studies have shown that annexin 6 is a major cardiac annexin. Studies in vitro have shown annexin 6 to be a potent regulator of the $\mathrm{Na}^{+} / \mathrm{Ca}^{2+}$ exchanger. $^{31)}$

Sixty kilo dalton heat shock protein (HSP60) was up-regulated in GSPE group compared to IR group. HSP60 has long been known as an important chaperonin and as having key folding functions within the mitochondria. However, more studies confirm that significant amounts of HSP60 are found in extra-mitochondrial locations. This extra-mitochondrial HSP60 in the heart has important anti-apoptotic functions. The decrease of HSP60 is sufficient to precipitate apoptosis. Redistribution of plasma HSP60 to the plasma membrane during hypoxia appears to contribute to the initiation of the apoptotic cascade with hypoxia and reoxygenation. ${ }^{32}$ The increase of HSP60 in GSPE group may have anti-apoptotic functions which may lead to the protection of GSPE against reperfusion injury.

We found that the subunit distribution of $\mathrm{Na}^{+} / \mathrm{K}^{+}$-ATPase was changed that the $\alpha 1$ subunit was decreased in non-GSPE treated group (IR group) compared to the sham group which was significantly increased in GSPE-treated group $(p<0.01)$. The sodium or $\mathrm{Na}^{+}, \mathrm{K}^{+}$pump is the familiar name for $\mathrm{Na}^{+} / \mathrm{K}^{+}$-ATPase $\left(\left(\mathrm{Na}^{+}, \mathrm{K}^{+}\right)\right.$-stimulated adenosine triphosphatase), an multi-subunit enzyme embedded in the plasma membrane. The $\mathrm{Na}^{+} / \mathrm{K}^{+}$-ATPase catalyzes the active uptake of $2 \mathrm{~K}^{+}$and extrusion of $3 \mathrm{Na}^{+}$at the expense of hydrolyzing ATP generated from cellular glycolysis and oxidative phosphorylation thereby generating steep concentration gradients for these ions. Thus, the cycle generates a net outward current generating the resting potential of cells, which is particularly important in neuronal and muscle function.

The $\mathrm{Na}^{+} / \mathrm{K}^{+}$-ATPase is composed of 3 polypeptide subunits $(\alpha, \beta, \gamma)$. The multi-pass transmembrane $\alpha$ subunit contains the binding sites for $\mathrm{Na}^{+}, \mathrm{K}^{+}$, ATP and cardiac glycosides. A class of naturally existing steroid compounds serve as specific inhibitors of the $\mathrm{Na}^{+} / \mathrm{K}^{+}$-ATPase. The $\beta$ subunit is often referred to as the "regulatory" subunit and is understood to be required for the biogenesis and activity of the enzyme complex that is believed to be a heterodimeric protomer $(\alpha-\beta){ }^{33,34)}$ The recently described $\gamma$ subunit is a transmembrane protein which is found to be associated with functional $\mathrm{Na}^{+} / \mathrm{K}^{+}$-ATPase. ${ }^{35)}$

Thus far, $4 \alpha(\alpha 1, \alpha 2, \alpha 3, \alpha 4), 3 \beta(\beta 1, \beta 2, \beta 3)$ and $1 \gamma$ isoform subunits have been identified in mammals. ${ }^{35-38)}$ However, other isoforms may exist and the search is on for novel isoform subunits that may confer unique kinetic prop- 
erties on the enzyme complex. The different isoforms ( $\alpha 1$, $\alpha 2, \alpha 3, \alpha 4)$ of the $\alpha$ subunit are widely expressed in an organ-specific manner. While the $\alpha 1$ isoform is expressed ubiquitously, the $\alpha 2$ isoform is present largely in skeletal muscle, heart, brain, adipocytes, vascular smooth muscle, and eye, as well as a number of other tissues. The $\alpha 3$ isoform is found almost exclusively in neurons and ovaries, but also occurs in white blood cells and heart of some species, such as humans. ${ }^{39,40)}$ The $\alpha 4$ isoform is expressed in sperm and is specifically synthesized at the spermatagonia stage, where it is required for sperm motility. ${ }^{41)}$ So we could believe reasonably that the tissue-specific distribution of the $\alpha$ isoforms indicates that each isoform exhibits a particular function associated with the tissue in which it is expressed. Studies directed toward determining the role of the $\alpha 1$ and $\alpha 2$ isoforms used animals in which the genes coding for these isoforms were knocked out. Animals lacking the expression of the $\alpha 1$ isoform died during embryogenesis. Specifically, embryos failed to develop beyond the blastocyst stage. This is expected as the $\alpha 1$ isoform is ubiquitously expressed and is required for multiple biological functions. Animals lacking the $\alpha 2$ isoform gene are born but die immediately following birth. ${ }^{42)}$

During myocardial ischemia, anaerobic metabolism results in intracellular acidosis, which activates the myocardial $\mathrm{Na}^{+}$, $\mathrm{H}^{+}$exchanger (NHE) to exclude $\mathrm{H}^{+}$in exchange for an influx of $\mathrm{Na}^{+}$in a one to one stoichiometric ratio. On reperfusion, the washout of extracellular $\mathrm{H}^{+}$further enhances this exchange process. ${ }^{43}$ ) Moreover, additional contributing factors to $\mathrm{Na}^{+}$overload include $\mathrm{Na}^{+}$influx through $\mathrm{Na}^{+}$channels and reduced efflux secondary to ischemia-induced depression of $\mathrm{Na}^{+} / \mathrm{K}^{+}$-ATPase activity. ${ }^{44)}$ As $\left[\mathrm{Na}^{+}\right] \mathrm{i}$ accumulates, the electrochemical gradient favouring $\mathrm{Ca}^{2+}$ efflux via the $\mathrm{Na}^{+}, \mathrm{Ca}^{2+}$ exchanger (NCX) is diminished and, depending on the severity, may ultimately promote $\mathrm{Ca}^{2+}$ influx through the reverse mode of the NCX. This $\mathrm{Ca}^{2+}$ overload may ultimately lead to deleterious consequences such as arrhythmogenesis. ${ }^{45)}$ An increase in intracellular $\mathrm{Ca}^{2+}$ can generate arrhythmias by activating the transient inward current $I_{t i}$, or by causing electrical uncoupling of cardiac myocytes, ${ }^{46}$ ) or by triggering delayed after depolarizations (DAD). ${ }^{47)}$ This may be part of the underlying mechanism of reperfusion arrhythmias.

Little is known regarding the direct involvement of the $\mathrm{Na}^{+} / \mathrm{K}^{+}$-ATPase in reperfusion-induced arrhythmias and regarding the possible underlying mechanisms that may lead to $\mathrm{Na}^{+} / \mathrm{K}^{+}$-ATPase disorders. Using iTRAQ we found that the subunit distribution of $\mathrm{Na}^{+} / \mathrm{K}^{+}$-ATPase was changed after reperfusion. $\mathrm{Na}^{+} / \mathrm{K}^{+}$-ATPase $\alpha 1$ subunit was decreased in non-GSPE treated group (IR group) compared to sham group which was significantly increased in GSPE-treated group. This change in subunit distribution may lead to the increase of $\mathrm{Na}^{+} / \mathrm{K}^{+}$-ATPase activity in GSPE-treated rats which in turn decreases $\left[\mathrm{Na}^{+}\right]_{\mathrm{i}}$. Then $\mathrm{Ca}^{2+}$ influx through the reverse mode of the NCX is diminished which will decrease the $\mathrm{Ca}^{2+}$ overload. This may be the potential mechanism of the protection of GSPE against reperfusion arrhythmias. Further study is needed to verify this hypothesis.

How GSPE increased the number of $\mathrm{Na}^{+} / \mathrm{K}^{+}$-ATPase $\alpha 1$ subunit after reperfusion was another interesting question. It is known that free radicals play an important role in reperfu- sion-induced cardiac arrhythmias. ${ }^{48)}$ Studies showed that reperfusion of the ischemic myocardium led to massive formation of oxygen free radicals. Then, direct evidence suggests that formation of oxygen free radicals may be important in the development of reperfusion-induced ventricular arrhythmias. Agents known to scavenge or inhibit the formation of oxygen free radicals could prevent reperfusion-induced arrhythmias, including ventricular tachycardia (VT) and ventricular fibrillation (VF), and improve the recovery of myocardium that is reperfused after ischemia. ${ }^{19}$ )

A significant amount of research has been conducted on GSPE. As mentioned above in the in vitro model GSPE exhibited concentration-dependent dramatic scavenging ability towards biochemically generated oxygen free radicals, and provided significantly better scavenging as compared to Vitamins $\mathrm{C}$ and $\mathrm{E}$. Many studies had shown that GSPE-treated rat myocardium was more resistant to ischemia-reperfusion injury as compared to the non GSPE-treated animals. ${ }^{10,15,19)}$ The GSPE-treated rats showed better post-ischemic ventricular recovery and a reduced incidence of reperfusion-induced VF and VT as compared to the corresponding non GSPEtreated animals. Reperfusion-induced cardiac injury could lead to a massive production of hydroxyl radicals in the reperfused isolated myocardium. Thus, GSPE strongly interfered with the hydroxyl radical formation and oxidative stress. The formation of hydroxyl radicals in the heart perfusate in GSPE-treated animals was significantly lower as compared to the non GSPE-treated animals. ${ }^{11,19)}$ Furthermore, a dramatic increase in the MDA concentration was significantly higher in the non GSPE-treated group, which was significantly reduced in GSPE-treated hearts. ${ }^{13)}$

In this study through comparative proteomics we found that $\mathrm{Na}^{+} / \mathrm{K}^{+}$-ATPase $\alpha 1$ subunit was decreased in IR group (non GSPE-treated) while the subunit was significantly increased in GSPE group. This change of subunit distribution may lead to the protection of GSPE against reperfusion arrhythmias by increasing the $\mathrm{Na}^{+} / \mathrm{K}^{+}$-ATPase activity. Ischemia/reperfusion induced free radicals generation which decreased $\mathrm{Na}^{+} / \mathrm{K}^{+}$-ATPase activity by reducing the total number of enzyme molecules. GSPE may protect myocardial tissues from reperfusion injury by reducing the free radical generation which resulted in the increase of $\mathrm{Na}^{+} / \mathrm{K}^{+}$-ATPase activity by increasing the total number of $\mathrm{Na}^{+} / \mathrm{K}^{+}$-ATPase molecules. However, the details of the mechanism underlying this protective effect need further study.

In conclusion, the present experiment for the first time showed that GSPE protected against severe reperfusion-induced VF and VT in rat hearts in vivo. $\mathrm{Na}^{+} / \mathrm{K}^{+}$-ATPase $\alpha 1$ subunit may be involved in the protection of GSPE on reperfusion arrhythmia injury. Using iTRAQ we found that the subunit distribution of $\mathrm{Na}^{+} / \mathrm{K}^{+}$-ATPase was changed after reperfusion. $\mathrm{Na}^{+} / \mathrm{K}^{+}$ATPase $\alpha 1$ subunit was decreased in IR group while it was significantly increased in GSPE group compared to sham group. This change in subunit distribution may lead to the increase of $\mathrm{Na}^{+} / \mathrm{K}^{+}$-ATPase activity in GSPE treated rats which would ultimately protect hearts from reperfusion arrhythmia injury. The decrease of free radical generation induced by GSPE may lead to the up-regulation of $\mathrm{Na}^{+} / \mathrm{K}^{+}$-ATPase $\alpha 1$ subunit. This may be the potential mechanism of the protection of GSPE against reperfusion arrhythmias. Since IR models of rat in vivo mimic clinical 
myocardial infarction or intracoronary thrombolysis or angioplasty situations, it is expected that GSPE may become effective antiarrhythmic drugs.

Acknowledgement iTRAQ analysis was performed by Beijing Protein Innovation. This work was supported by the National Natural Science Foundation of China (30700884, 30873145) and Shandong Distinguished Middle-aged and Young Scientist Encourage and Reward Foundation (BS2009SW015).

\section{REFERENCES}

1) Braunwald E., Kloner R. A., J. Clin. Invest., 76, 1713-1719 (1985).

2) Yellon D. M. B. G., Heart, 83, 381-387 (2000).

3) Moens A. L., Claeys M. J., Timmermans J. P., Vrints C. J., Int. J. Cardiol., 100, 179-190 (2005).

4) Manning A. S. H. D., J. Mol. Cell. Cardiol., 16, 497-518 (1984).

5) Tzivoni D. K. A., Granot H., Gottlieb S., Benhorin J., Stern S., Am. Heart J., 105, 323-325 (1983).

6) Dennis S. C., Coetzee W. A., Cragoe E. J. Jr., Opie L. H., Circ. Res., 66, 1156-1159 (1990).

7) Manning A. S., Coltart D. J., Hearse D. J., Circ. Res., 55, 545-548 (1984).

8) Bernier M., Hearse D. J., Manning A. S., Circ. Res., 58, 331-340 (1986).

9) Grech E. D., Dodd N. J., Bellamy C. M., Perry R. A., Morrison W. L., Ramsdale D. R., Lancet, 341, 990-991 (1993).

10) Sato M., Bagchi D., Tosaki A., Das D. K., Free Radic. Biol. Med., 31, $729-737$ (2001)

11) Sato M., Maulik G., Ray P. S., Bagchi D., Das D. K., J. Mol. Cell. Cardiol., 31, 1289-1297 (1999).

12) Bagchi D., Bagchi M., Stohs S. J., Das D. K., Ray S. D., Kuszynski C. A., Joshi S. S., Pruess H. G., Toxicology, 148, 187-197 (2000).

13) Bagchi D., Sen C. K., Ray S. D., Das D. K., Bagchi M., Preuss H. G., Vinson J. A., Mutat. Res., 523-524, 87—97 (2003).

14) Shao Z. H., Wojcik K. R., Dossumbekova A., Hsu C., Mehendale S. R., Li C. Q., Qin Y., Sharp W. W., Chang W. T., Hamann K. J., Yuan C. S., Hoek T. L., J. Cell. Biochem., 107, 697-705 (2009).

15) Liang Y., Qiu J., Gao H. Q., Li B. Y., J. Nutr. Sci. Vitaminol., 55, $223-$ 230 (2009).

16) Klein C., Garcia-Rizo C., Bisle B., Scheffer B., Zischka H., Pfeiffer F., Siedler F., Oesterhelt D., Proteomics, 5, 180-197 (2005).

17) Ross P. L., Huang Y. N., Marchese J. N., Williamson B., Parker K., Hattan S., Khainovski N., Pillai S., Dey S., Daniels S., Purkayastha S., Juhasz P., Martin S., Bartlet-Jones M., He F., Jacobson A., Pappin D. J., Mol. Cell. Proteomics, 3, 1154-1169 (2004).

18) Xue Y. X., Aye N. N., Hashimoto K., Eur. J. Pharmacol., 317, 309316 (1996).

19) Pataki T., Bak I., Kovacs P., Bagchi D., Das D. K., Tosaki A., Am. J. Clin. Nutr, 75, 894-899 (2002).

20) Bulkely B. H., Hutchins G. M., Circulation, 56, 906-913 (1977).
21) DeWood M. A., Spores J., Notske R., Mouser L. T., Burroughs R., Golden M. S., Lang H. T., N. Engl. J. Med., 303, 897—902 (1980).

22) Reimer K. A., Lowe J. E., Rasmussen M. M., Jennings R. B., Circulation, 56, 786-794 (1977).

23) Pratt C. M., Waldo A. L., Camm A. J., Am. J. Cardiol., 81, 24d-34d (1998).

24) Sato M., Maulik G., Bagchi D., Das D. K., FASEB J., 13, A1438A1438 (1999).

25) Bagchi D., Garg A., Krohn R. L., Bagchi M., Tran M. X., Stohs S. J., Res. Commun. Mol. Pathol. Pharmacol., 95, 179-189 (1997).

26) Wallin E., von Heijne G., Protein Sci., 7, 1029-1038 (1998).

27) Hopkins A. L., Groom C. R., Nat. Rev. Drug Discov., 1, 727-730 (2002).

28) Gygi S. P., Rist B., Gerber S. A., Turecek F., Gelb M. H., Aebersold R., Nat. Biotechnol., 17, 994-999 (1999).

29) Sobota A., Bandorowicz J., Jezierski A., Sikorski A. F., FEBS Lett., 315, 178-182 (1993).

30) Hill W. G., Kaetzel M. A., Kishore B. K., Dedman J. R., Zeidel M. L., J. Gen. Physiol., 121, 413- 425 (2003).

31) Sobota A., Cusinato F., Luciani S., Biochem. Biophys. Res. Commun., 172, 1067-1072 (1990).

32) Knowlton A. A., Gupta S., Cardiovasc. Toxicol., 3, 263-268 (2003).

33) Brotherus J. R., Jacobsen L., Jorgensen P. L., Biochim. Biophys. Acta, 731, 290-303 (1983).

34) Fambrough D. M., Lemas M. V., Hamrick M., Emerick M., Renaud K. J., Inman E. M., Hwang B., Takeyasu K., Am. J. Physiol., 266, C579C589 (1994).

35) Mercer R. W., Biemesderfer D., Bliss D. P. Jr., Collins J. H., Forbush B. 3rd, J. Cell. Biol., 121, 579-586 (1993).

36) Martin-Vasallo P., Ghosh S., Coca-Prados M., J. Cell. Physiol., 141, $243-252$ (1989)

37) Shamraj O. I., Lingrel J. B., Proc. Natl. Acad. Sci. U.S.A., 91, 1295212956 (1994).

38) Malik N., Canfield V. A., Beckers M. C., Gros P., Levenson R., J. Biol. Chem., 271, 22754-22758 (1996).

39) Shamraj O. I., Melvin D., Lingrel J. B., Biochem. Biophys. Res. Commun., 179, 1434-1440 (1991).

40) Stengelin M. K., Hoffman J. F., Proc. Natl. Acad. Sci. U.S.A., 94, 5943-5948 (1997)

41) Woo A. L., James P. F., Lingrel J. B., J. Membr. Biol., 169, 39-44 (1999).

42) James P. F., Grupp I. L., Grupp G., Woo A. L., Askew G. R., Croyle M. L., Walsh R. A., Lingrel J. B., Molecular Cell, 3, 555-563 (1999).

43) Lazdunski M., Frelin C., Vigne P., J. Mol. Cell. Cardiol., 17, 10291042 (1985).

44) Bers D. M., Barry W. H., Despa S., Cardiovasc. Res., 57, 897-912 (2003).

45) Pogwizd S. M., Drugs, 63, 439—452 (2003).

46) Benndorf K., Friedrich M., Hirche H., Pflugers Arch., 418, 248-260 (1991).

47) Ferrier G. R., Moffat M. P., Lukas A., Circ. Res., 56, 184-194 (1985).

48) Liu P. H. C., Nagele R., Wong P. Y., Am. J. Physiol., 272, H2327H2336 (1997). 